\title{
Selection, Development and Results for The RESOLVE Regolith Volatiles Characterization Analytical System
}

\author{
Dale E. Lueck ${ }^{1}$, Janine E. Captain ${ }^{1}$, Tracy L. \\ Gibson², Barbara V. Peterson², Cristina M. Berger², \\ Lanfang Levine ${ }^{3}$
}

${ }^{1}$ NASA, ${ }^{2}$ ASRC, ${ }^{3}$ Dynamac, all at J.F. Kennedy Space Center 


\section{RESOLVE:}

\section{A Bridge Between Early Lunar ISRU \& Lunar Science Objectives}

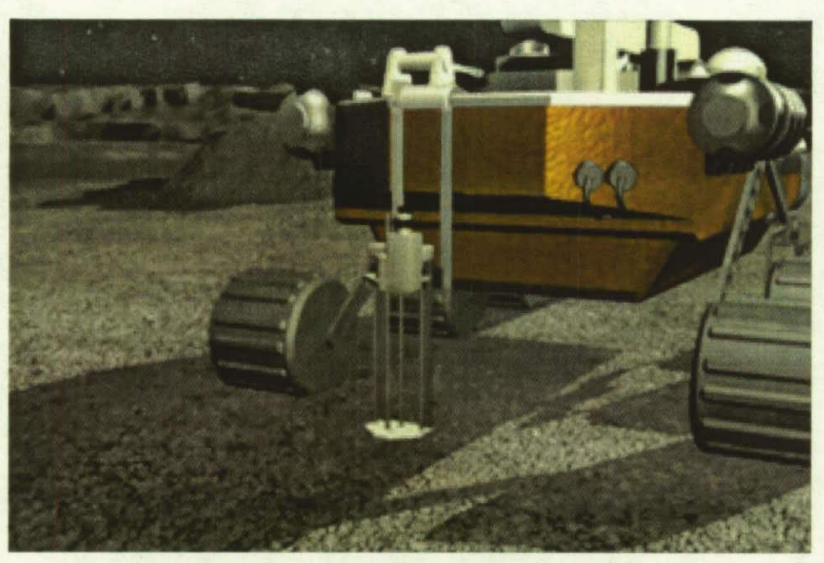




\section{Hydrogen or Water on the Moon?}

RESOL VE: Regolith \& Environment Science and Oxygen \& Lunar Volatile Extraction

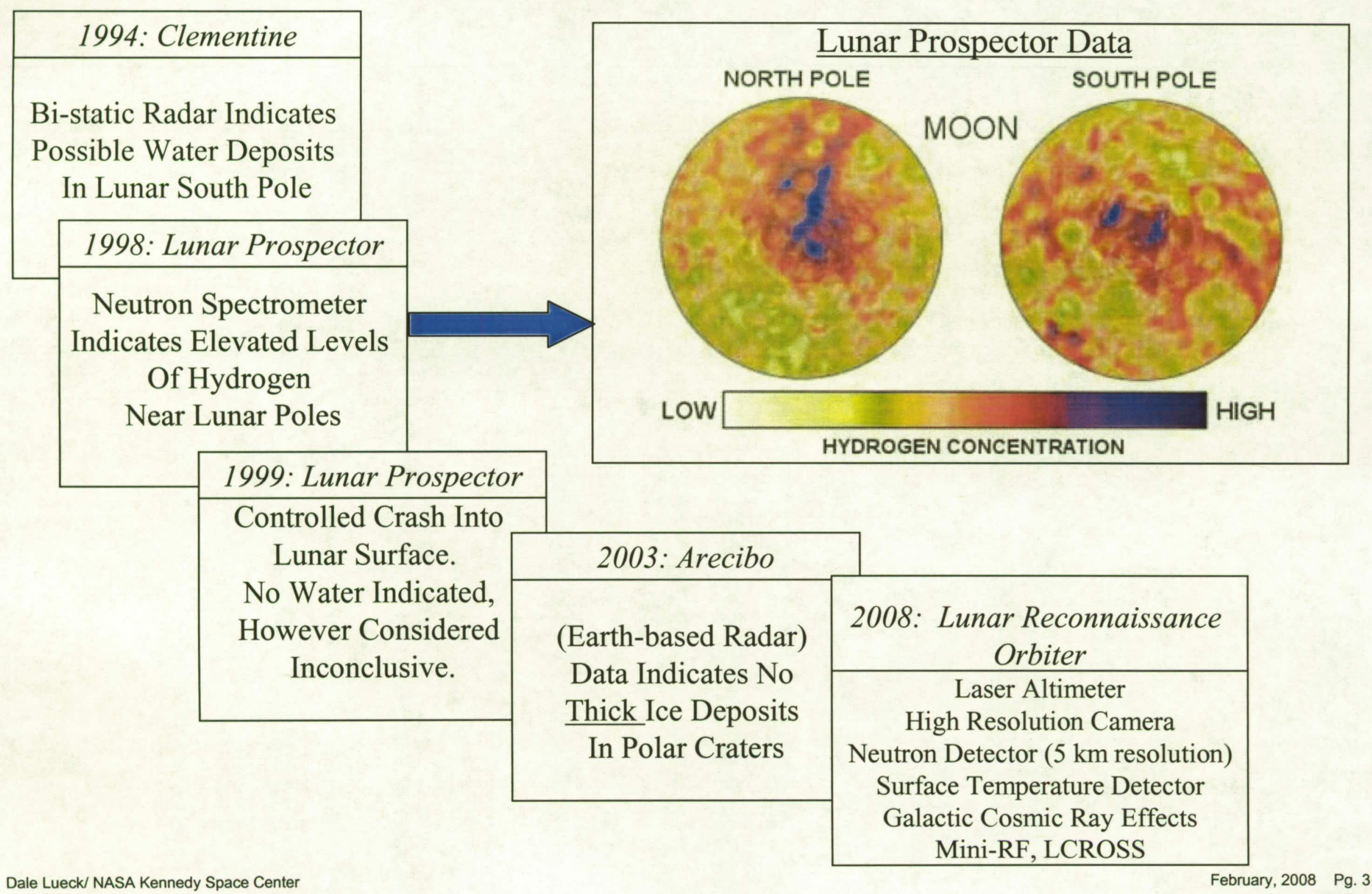




\section{Sources of Polar Hydrogen}

RESOLVE; Regolith \& Environment Science and Oxygen \& Lunar Volatile Extraction

- Solar wind:

- Directly implanted $\mathrm{H}$ with preferential retention in cold traps

- Released and transported from non-polar soil grains

- Impact of wet objects:

- Hydrous meteorites (and micrometeorites)

- Comets

- Giant molecular clouds

- Planetary degassing

- Possible small contribution

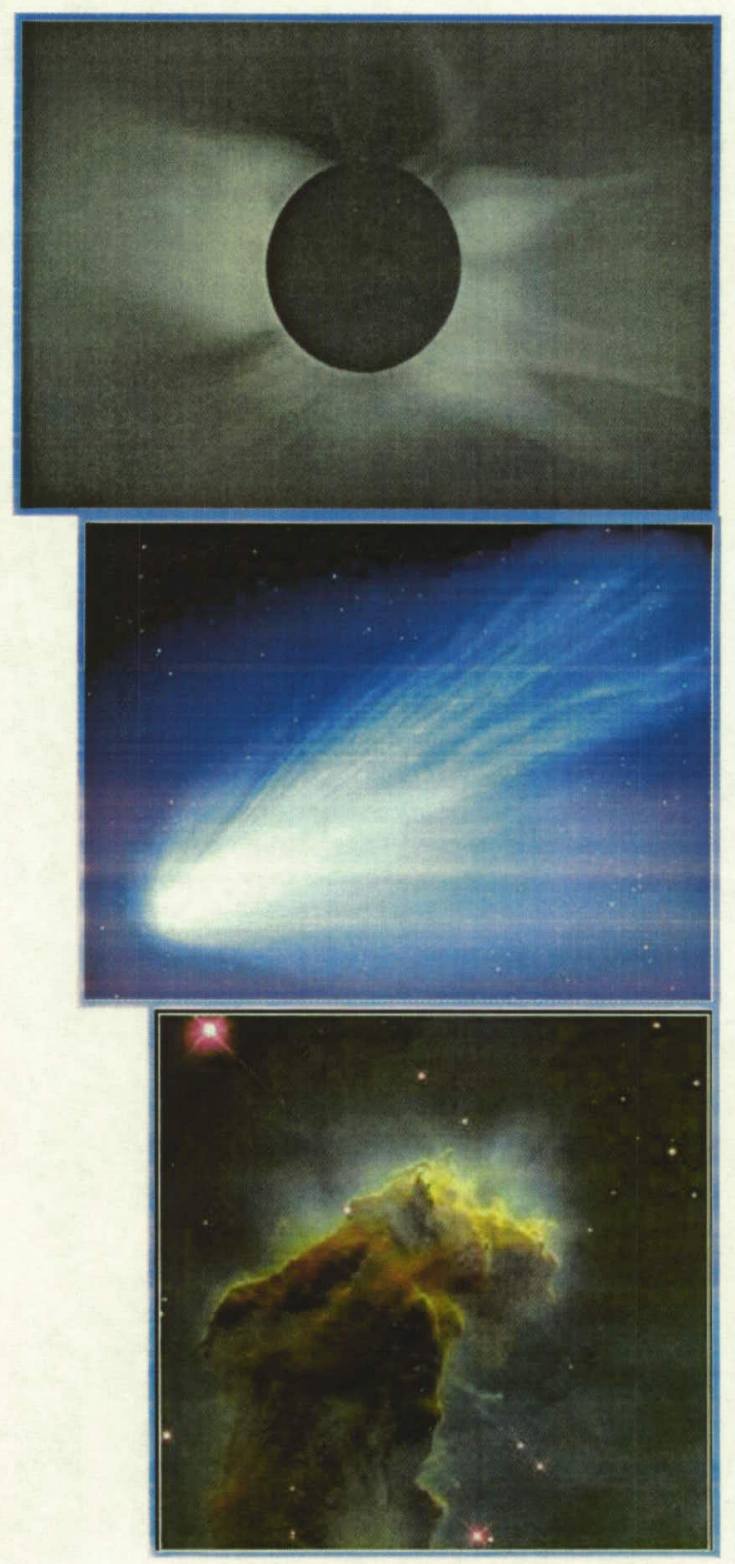

Solar Wind

Comets

Giant

Molecular

Clouds 


\section{Distinguishing Sources of Volatiles}

RESOLVE: Regolith \& Environment Science and Oxygen \& Lunar Volatile Extraction

\begin{tabular}{|l|l|}
\hline Source & Properties \\
\hline Solar Wind only & $\begin{array}{l}\text { Solar } \mathrm{D} / \mathrm{H}\left(25 \times 10^{-6}\right) \text { and } \mathrm{C}^{12} / \mathrm{C}^{13} \\
\text { No or very little } \mathrm{H}_{2} \mathrm{O}\end{array}$ \\
\hline $\begin{array}{c}\text { Continuous delivery of } \\
\text { solar wind-derived } \\
\text { gases }\end{array}$ & $\begin{array}{l}\text { Solar } \mathrm{D} / \mathrm{H}\left(25 \times 10^{-6}\right) \text { and } \mathrm{C}^{12} / \mathrm{C}^{13} \text { (but chance } \\
\text { of fractionation) } \\
\text { Low concentrations of } \mathrm{H}_{2} \mathrm{O} \\
\text { Possibly roughly uniform distribution of } \mathrm{H}_{2} \mathrm{O}\end{array}$ \\
\hline $\begin{array}{c}\text { Comets, carbonaceous } \\
\text { asteroids }\end{array}$ & $\begin{array}{l}\left.\text { High D/H (100-400 } \times 10^{-6}\right) \text { (chance of } \\
\text { fractionation) } \\
\text { Patches of high } \mathrm{H}_{2} \mathrm{O} \text { concentrations } \\
\text { Blocks of ice } \\
\text { Other volatiles } \\
\text { Organic compounds }\end{array}$ \\
\hline Giant molecular clouds & $\begin{array}{l}\text { Very high D/H }\left(10,000 \times 10^{-6}\right) \\
\text { Organic compounds } \\
\text { Likely to be in concentrated in thin layers? }\end{array}$ \\
\hline
\end{tabular}




\section{Ground Truth Data Needed}

RESOLVE: Regolith \& Environment Science and Oxygen \& Lunar Volatile Extraction

Gain knowledge to guide future mission architecture decisions to allow utilization of in-situ resources to their fullest extent and optimum benefit.

To do this we must:

- Understand the resources (Are there extant resources worth going after?)

- What resources are there?

- How abundant is each resource?

- What are the real and vertical distributions and hetero/homogeneity?

- How much energy is required to evolve/separate each resource?

- Understand environment impact on extraction and processing hardware

- What is the local temperature, pressure, radiation environment?

- What are the physical/mineralogical properties of the local regolith?

- Are there extant volatiles that are detrimental to processing hardware or humans?

- Design and utilize hardware to the maximum extent possible that has applicability to follow-on ISRU missions

- Can we effectively separate and capture volatiles of interest?

- Can we execute repeated processing cycles (reusable chamber seals, tolerance to thermal cycles)?

- Engage the public about lunar missions and 'living off the land' 


\section{RESOLVE}

Regolith \& Environment Science \& Oxygen \& Lunar Volatile Extraction 


\section{RESOLVE Design Working Assumptions}

RESOLVE: Regolith \& Environment Science and Oxygen \& Lunar Volatile Extraction

\section{Resource Working Assumptions}

- Hydrogen-source (from satellite observations) shall be on the order of 1000 ppm of regolith mass.

- Chemical form of hydrogen is unknown

- Estimated average concentration of hydrogen-source is $0.1 \%$ to $0.9 \%$ by weight in regolith

- Hydrogen-source most likely hydrogen $\left(\mathrm{H}_{2}\right)$ or water $\left(\mathrm{H}_{2} \mathrm{O}\right)$, but other possibilities include: $\mathrm{NH}_{3}, \mathrm{CH}_{4}, \mathrm{H}_{2} \mathrm{~S}, \mathrm{HCN}$, and $\mathrm{CH}_{3} \mathrm{OH}$, but these are expected to be less than $2 \%$ of the water conc.

- Several other volatiles are likely: $\mathrm{CO}_{2}, \mathrm{CO}, \mathrm{He}, \mathrm{Ne}, \mathrm{Ar}$, etc.

- Composition and concentration of volatiles in polar craters is unknown.

- Buried concentrations of ice to lightly held hydrogen gas is possible. System must handle all possibilities.

- Core drill will deliver $15 \mathrm{~mm} \times 25 \mathrm{~cm} 1 / 4$ cores for heating and analysis

- Estimated volume of $\mathrm{H} 2$ or $\mathrm{H} 2 \mathrm{O}$ is 1 liter + other volatiles

- System should analyze, separate and capture H2 \& H2O 


\section{RESOLVE Objectives}

RESOLVE: Regolith \& Environment Science and Oxygen \& Lunar Volatile Extraction

Resource

Characterization

In-Situ Resource Utilization Demo

Additional experiment goals if payload \& mission design allow.

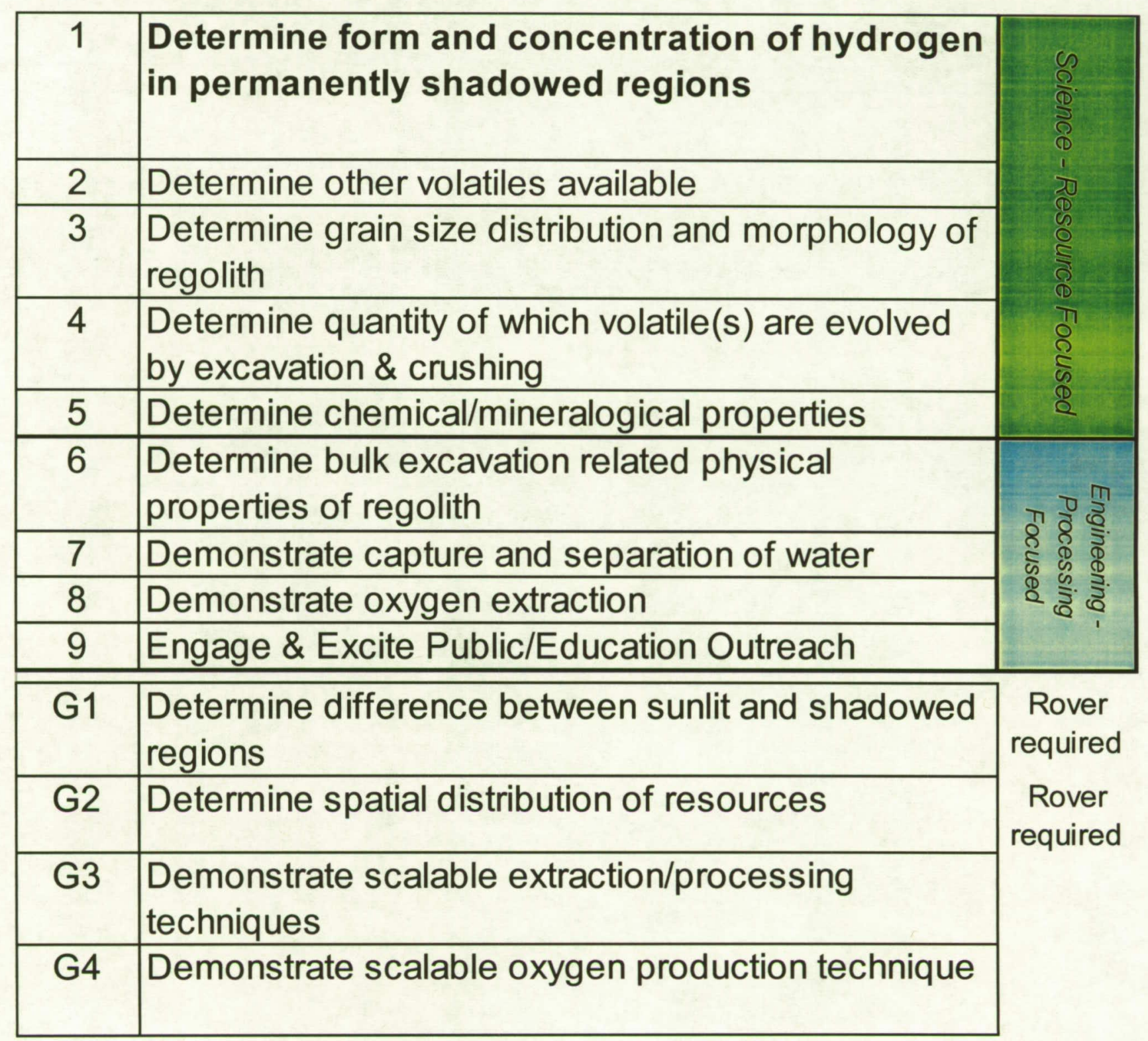




\section{Brief RESOLVE Overview}

RESOL VE: Regolith \& Environment Science and Oxygen \& Lunar Volatile Extraction

- RESOLVE - Regolith \& Environment Science and Oxygen \& Lunar Volatile Extraction

- Goal - identify and quantify volatiles, demonstrate ISRU, engage the public interest in 'living off the land' technology
- RESOLVE incorporates 5 modules

- EBRC (Excavation and Bulk Regolith Characterization)

- ERPC (Environment and Regolith Physical Characterization)

- ROE (Regolith Oxygen Extraction)

- RVC (Regolith Volatile Characterization)

- LWRD (Lunar Water Resource Demonstration)

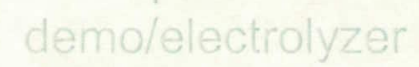




\section{Comparison between GC and MS}

RESOLVE: Regolith \& Environment Science and Oxygen \& Lunar Volatile Extraction

- Gas Chromatography with thermal conductivity detectors

- (+) we expect large concentrations (\% range) which work well with TCDs

- (+) well established columns for separation and measurement of compounds that are expected

- (+) measures water

- (-) unknown compounds may co-elute and be misidentified

- (-) very low levels of some compounds $\left(\mathrm{He}^{3}\right)$ cannot be detected, most compounds detectable down to 1000ppm in the vapor phase
- Mass Spectrometer

- (+) Unique fingerprint when compounds are isolated

- (-) Matrix effects

- Pressure of sample

- Viscosity of gas varies with composition and directly affects response

- (-) difficult to interpret spectra with multiple compounds

- (-) no industrial experience with water quantitation by MS

- (-) attempts to use MS analysis with RWGS system never produced realistic mass balance

- (-) cannot differentiate between same mass compounds (ex. $\mathrm{N}_{2}$ and $\mathrm{CO}$, or $\mathrm{HD}$ and $\mathrm{He}^{3}$ ) 


\section{Selection of Carrier Gas}

RESOLVE: Regolith \& Environment Science and Oxygen \& Lunar Volatile Extraction

- We would like a single injection and carrier gas to analyze $\mathrm{H} 2, \mathrm{He}$, and all the other gases of interest

- Whatever the carrier gas, that gas will NOT be analyzed!

- Neon appears to be a good choice, but H2 \& He peaks will be reversed from the other gases... No Problem!

\begin{tabular}{c|l|c}
\hline Molecular Formula & Name & Thermal Conductivity $\mathbf{( m W} / \mathbf{m} \mathbf{~ K})$ \\
\hline $\mathrm{Ar}$ & Argon & 22.6 \\
$\mathrm{H}_{2}$ & Hydrogen & 230.4 \\
$\mathrm{He}$ & Helium & 190.6 \\
$\mathrm{Ne}$ & Neon & 60.3 \\
$\mathrm{O}_{2}$ & Oxygen & 33.7 \\
$\mathrm{~N}_{2}$ & Nitrogen & 32.3 \\
$\mathrm{H}_{2} \mathrm{O}$ & Water & 27.1 \\
$\mathrm{CH}_{4}$ & Methane & 49.1 \\
$\mathrm{CO}_{2}$ & Carbon Dioxide & 25.1 \\
$\mathrm{CO}$ & Carbon Monoxide & 32.3 \\
\hline
\end{tabular}




\section{Adjusting Detector Power for Neon}

RESOLVE: Regolith \& Environment Science and Oxygen \& Lunar Volatile Extraction

\begin{tabular}{l|l|r|r|r}
\hline \multirow{2}{*}{ Gas Name } & Maximum & \multicolumn{3}{|c}{ Thermal Conductivity, $\mathbf{~ W / m ~ K}$} \\
\cline { 3 - 5 } & Power $(\mathbf{m W})$ & $\mathbf{5 0 0} \mathbf{~ K}$ & $\mathbf{5 2 3} \mathbf{~ K}$ & $\mathbf{6 0 0} \mathbf{~ K}$ \\
\hline Argon & 28 & 26.8 & 39.6 & 44.0 \\
Helium & 115 & 222.3 & 230.0 & 252.4 \\
Hydrogen & 115 & 274.0 & 280.0 & 300.0 \\
Neon & $\mathbf{4 6}$ & 69.9 & 73.5 & 78.7 \\
\hline
\end{tabular}

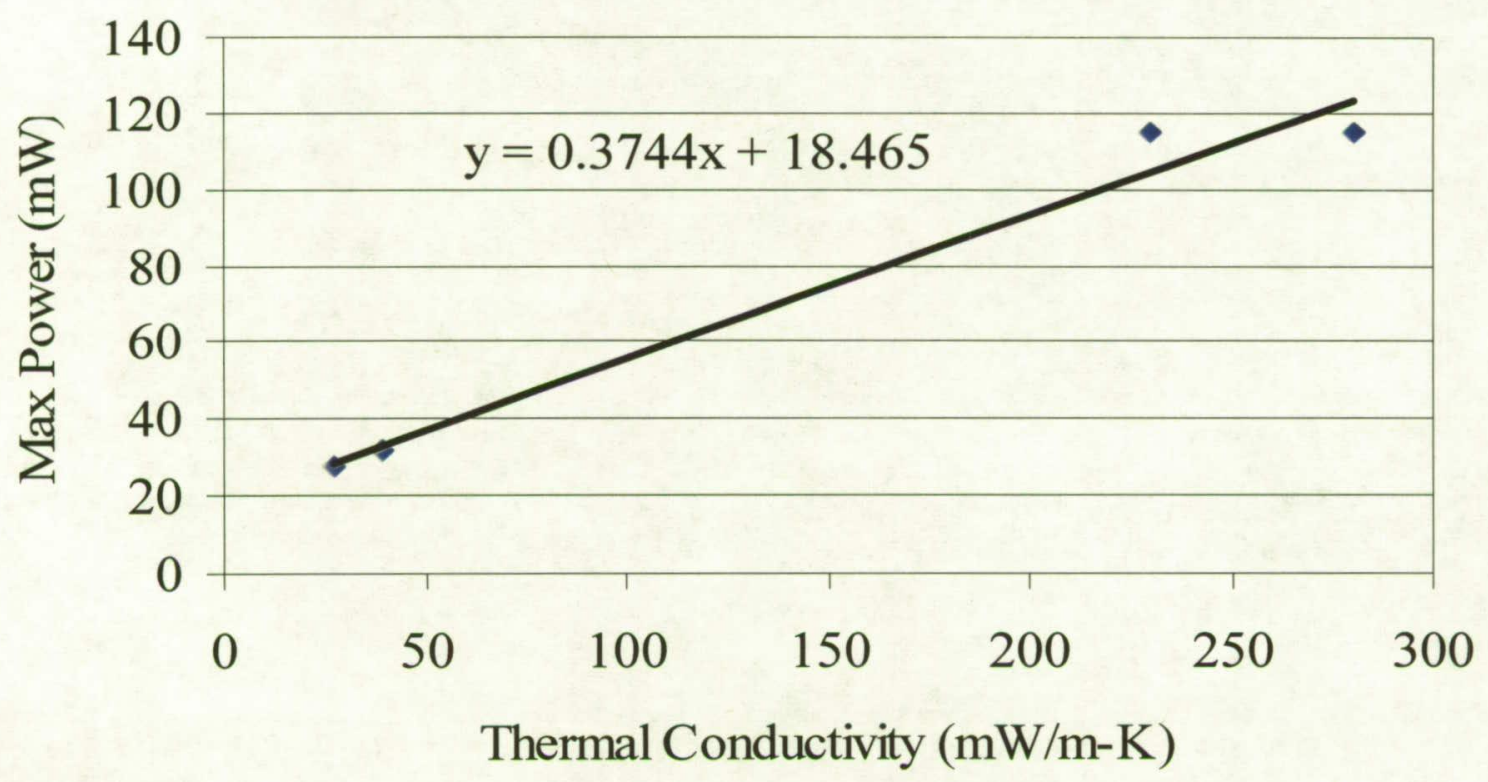




\section{Engineering Breadboard Unit (EBU) 1 Accomplishments}

RESOLVE; Regolith \& Environment Science and Oxygen \& Lunar Volatile Extraction

- Regolith Volatiles Characterization

- Regolith Oven Complete and Tested (150 C)

- Oven is vibro-fluidized to ensure even heating (validated by testing)

- Oven is heated in steps to provide data on release temperatures

- Siemens Miniature Gas Chromatograph Modified and Calibrated to meet detection objectives.

- Detection limits in vapor phase: $2-20 \%$ water, 1000 ppm - 100\% $\mathrm{H} 2, \mathrm{He}, \mathrm{N} 2, \mathrm{O} 2, \mathrm{CH} 4, \mathrm{CO}, \mathrm{CO} 2$.

- H2S separated but not calibrated.

- $\mathrm{NH} 3, \mathrm{HCN}$, formaldehyde, and methanol not tested yet 


\section{Manual Control Interface}

\section{RESOLVE: Regolith \& Environment Science and Oxygen \& Lunar Volatile Extraction}

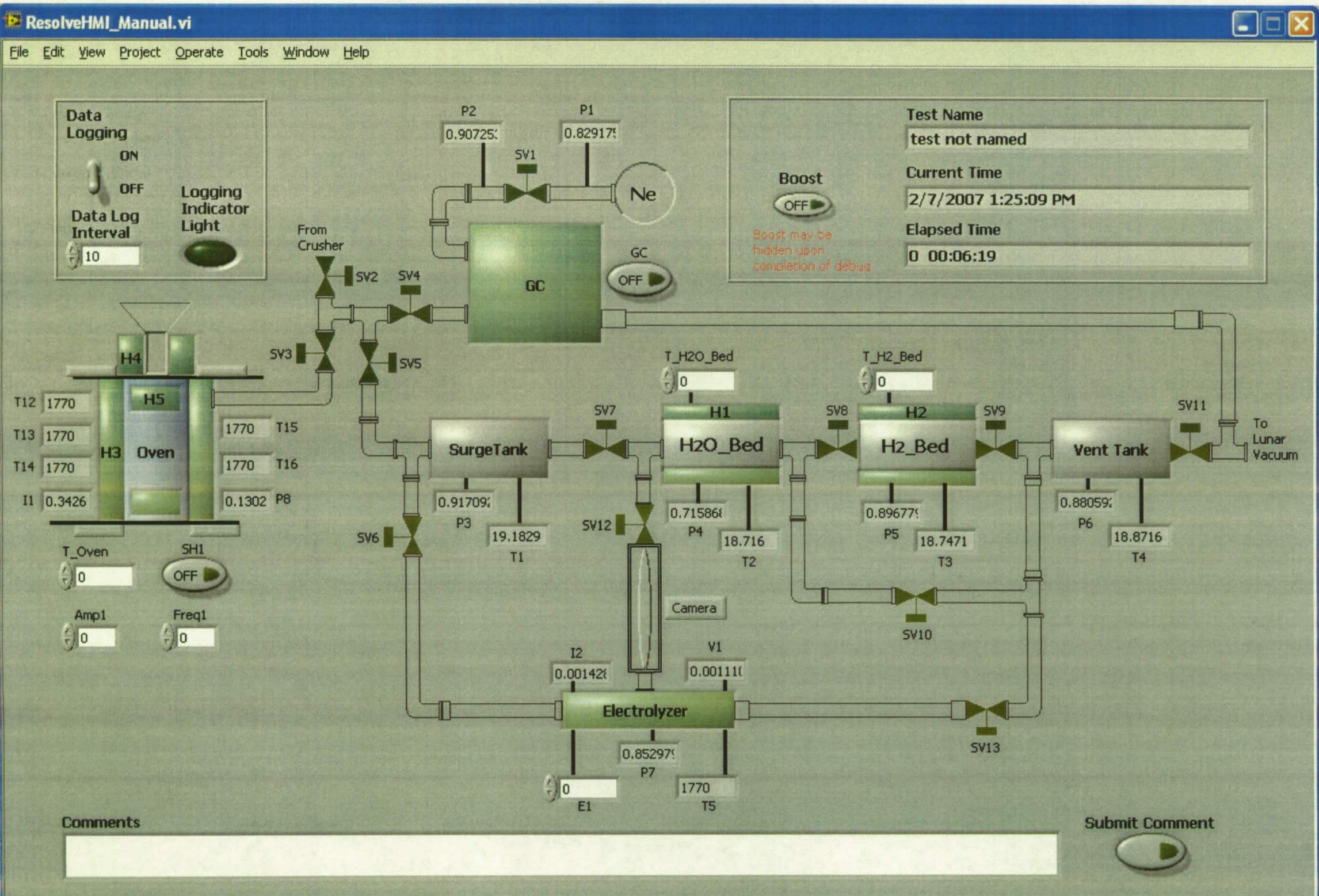




\section{Drill \& Regolith Volatiles \\ Characterization Photos}

RESOLVE; Regolith \& Environment Science and Oxygen \& Lunar Volatile Extraction

Details of Siemens MicroSAM GC

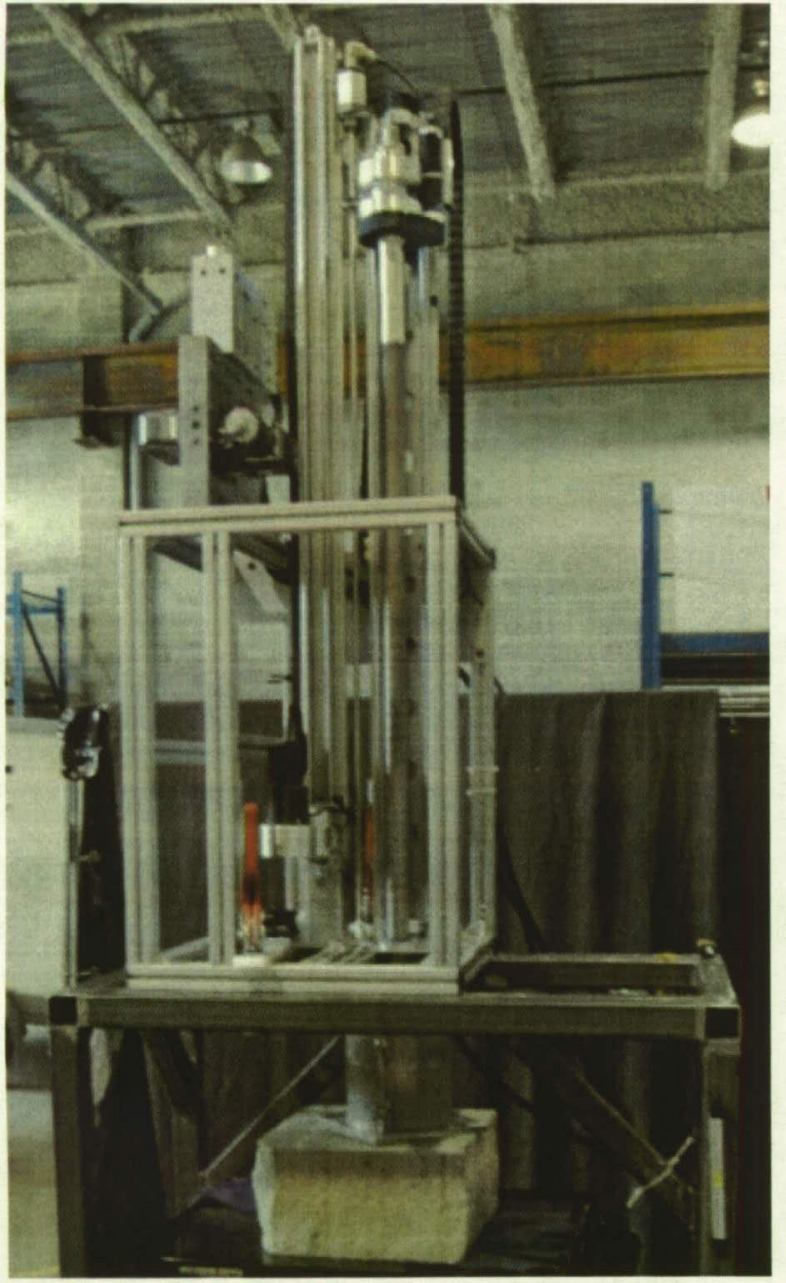

Drill \& Crusher (Northern Center for Advanced Technology) Dale Lueck/ NASA Kennedy Space Center

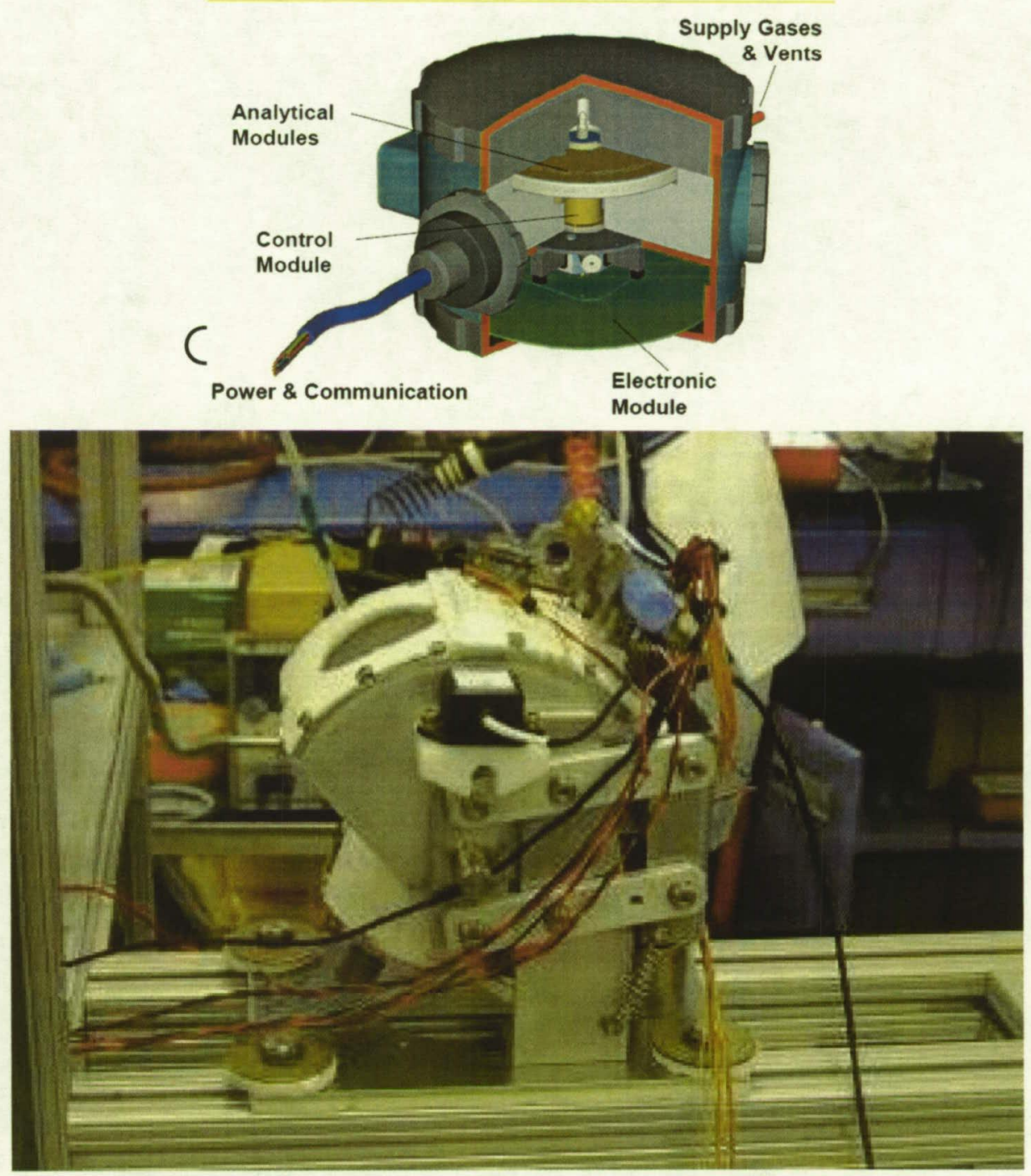

Regolith Volatiles Characterization Ov veben 


\section{GC Application Module}

RESOL VE: Regolith \& Environment Science and Oxygen \& Lunar Volatile Extraction

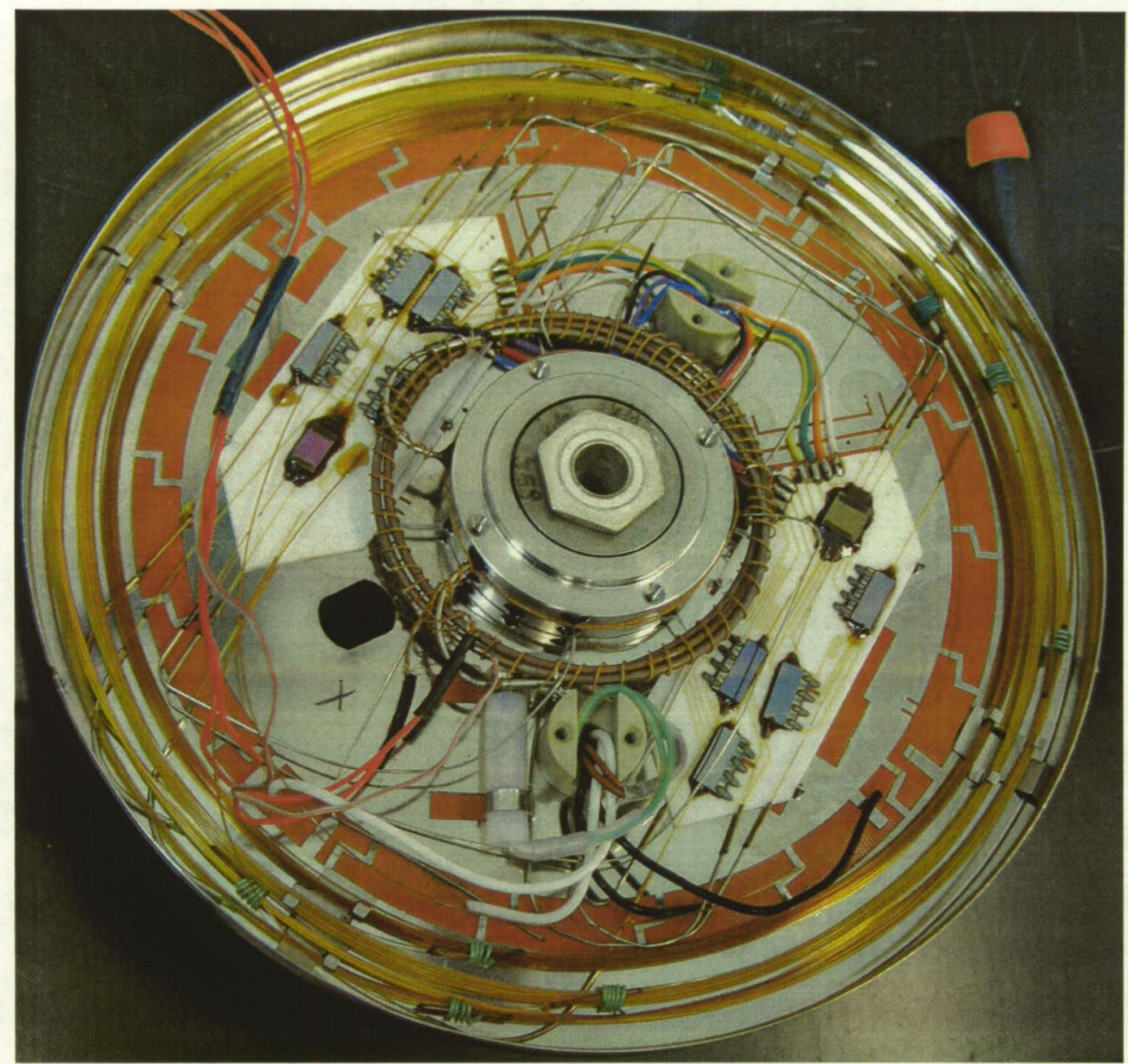




\section{RESOL VE: Regolith \& Environment Science and Oxygen \& Lunar Volatile Extraction}
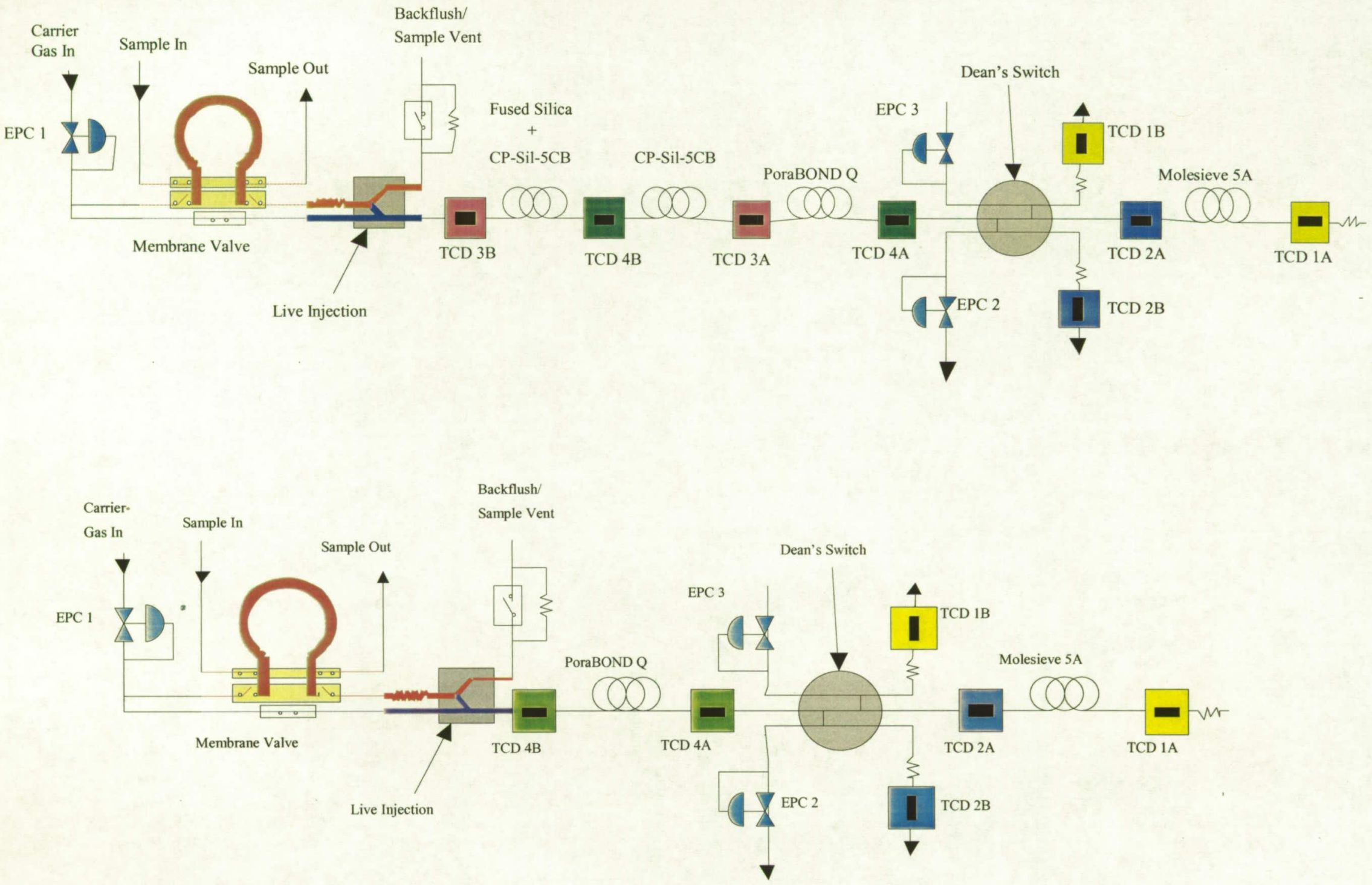


\section{Separation of Light Gases}

RESOLVE: Regolith \& Environment Science and Oxygen \& Lunar Volatile Extraction

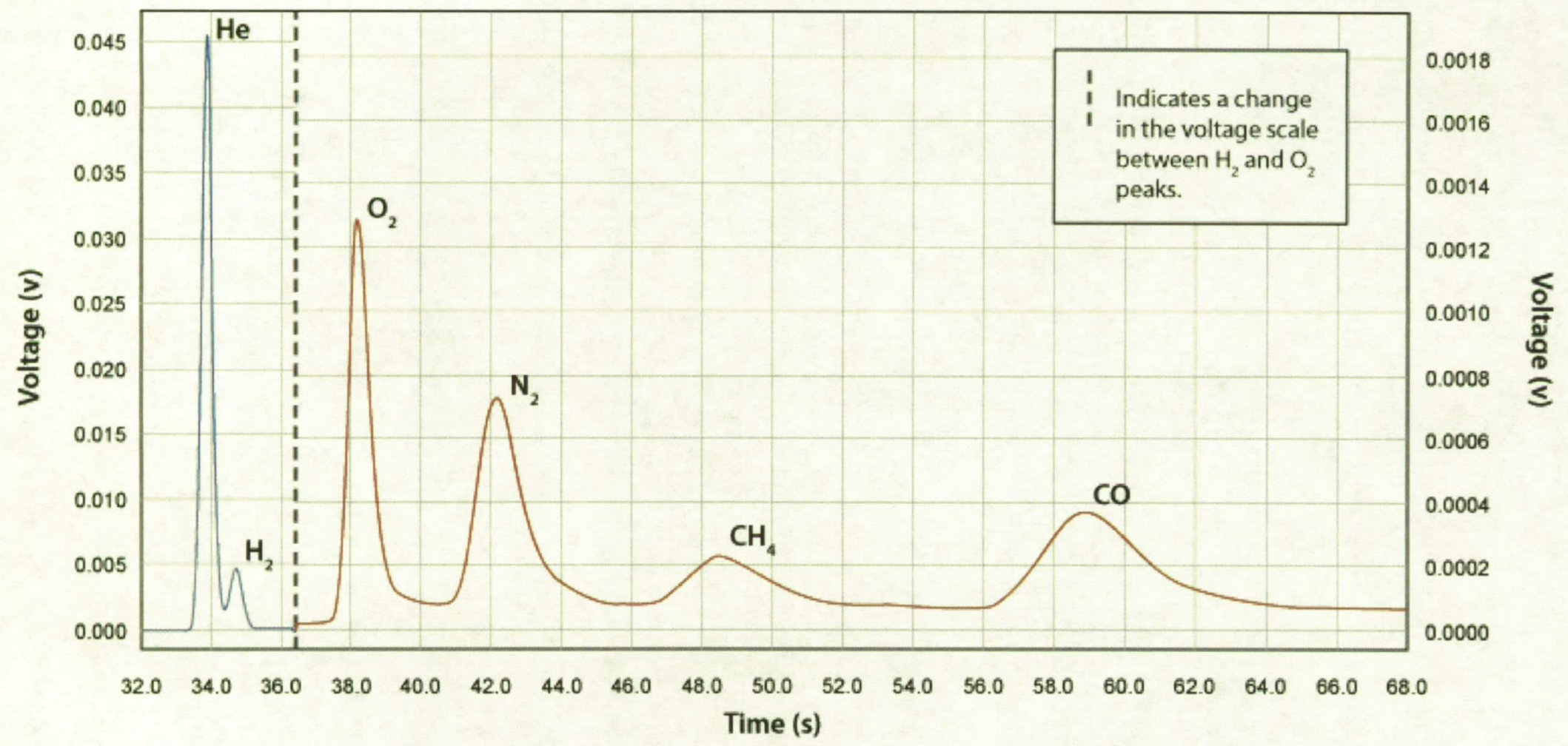




\section{EBU 2 Calibration Results Hydrogen}

RESOLVE; Regolith \& Environment Science and Oxygen \& Lunar Volatile Extraction

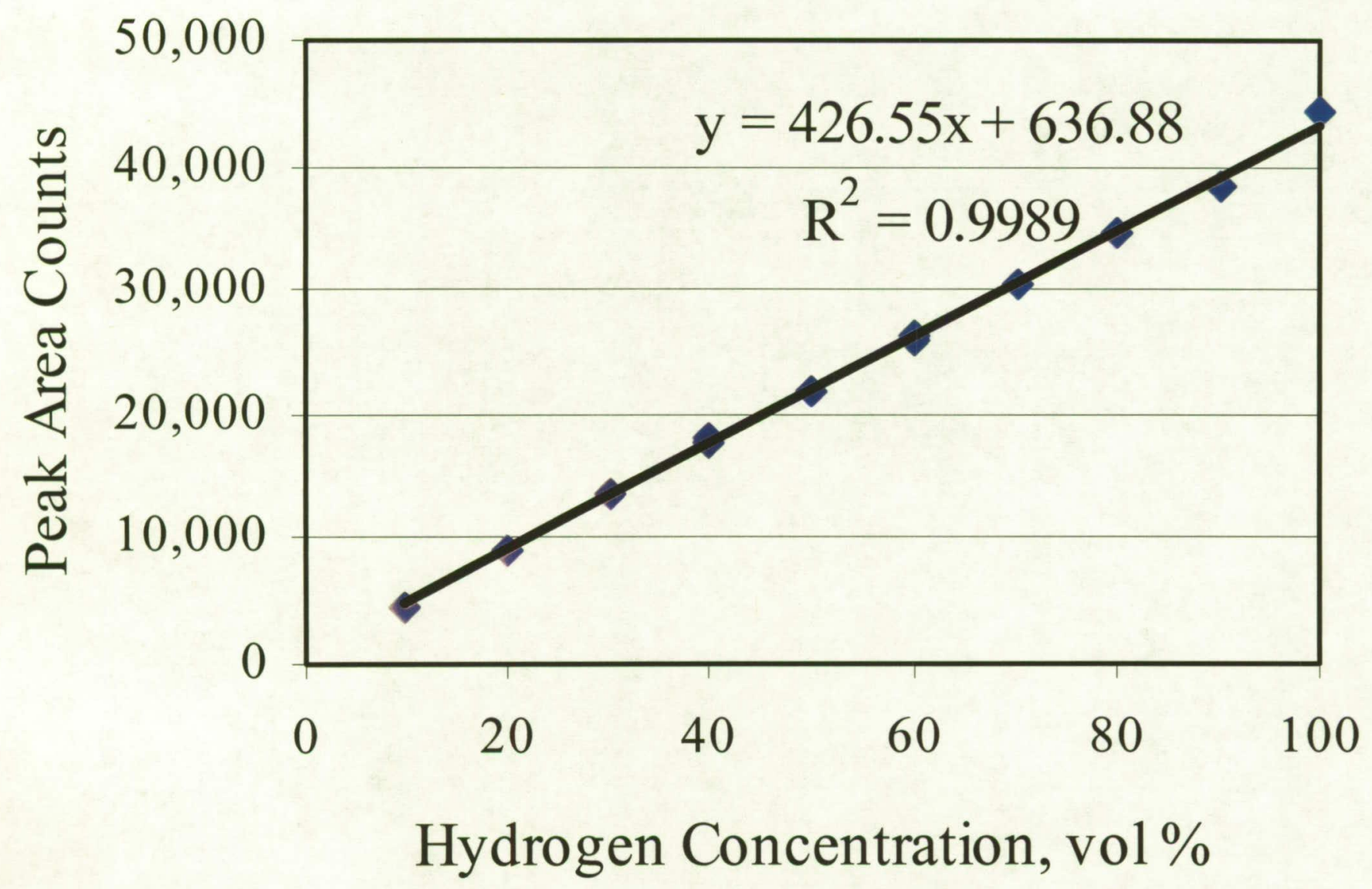




\section{EBU 1 Calibration Results Water}

RESOL VE: Regolith \& Environment Science and Oxygen \& Lunar Volatile Extraction

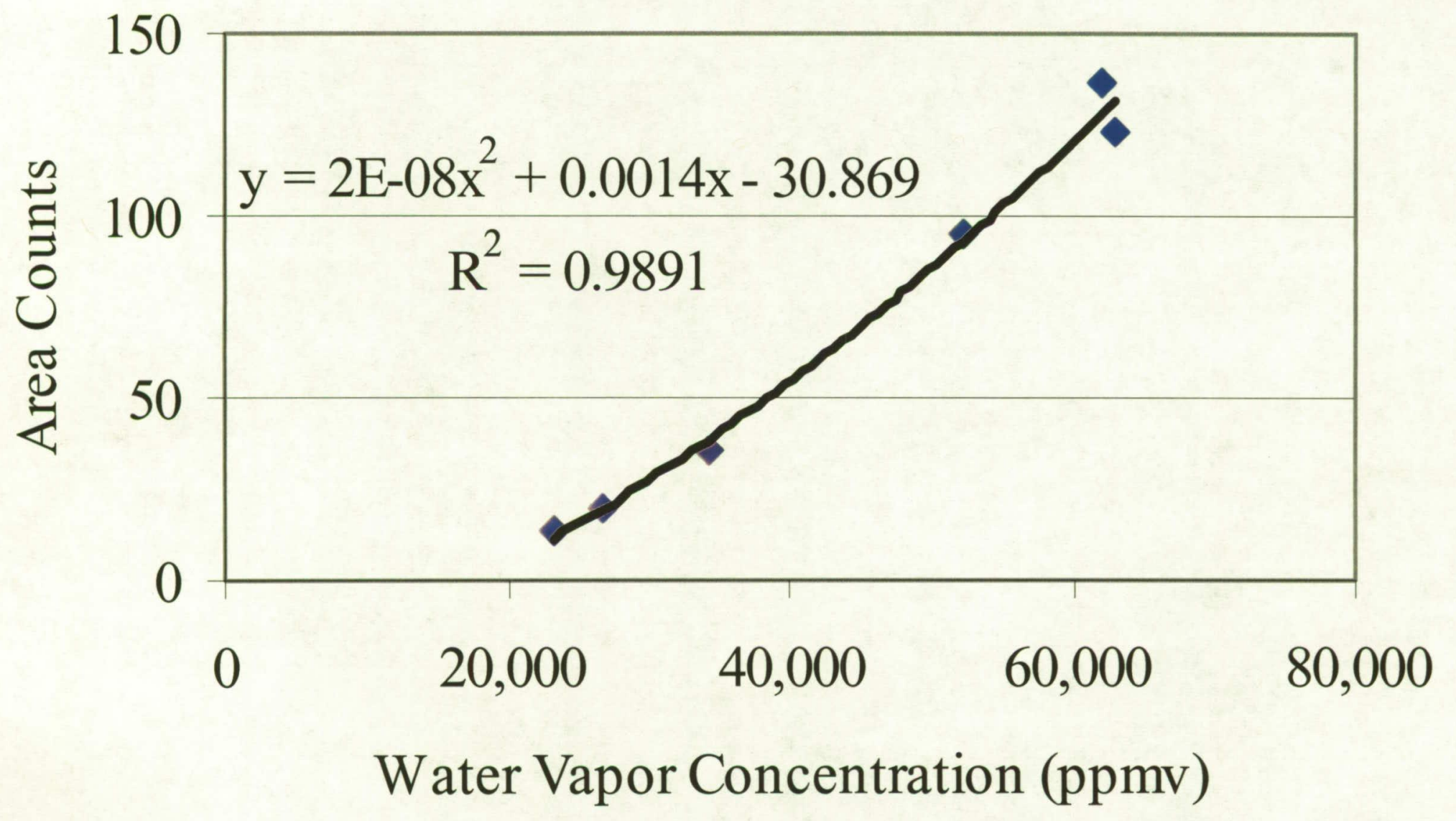




\section{The Path Forward}

RESOLVE: Regolith \& Environment Science and Oxygen \& Lunar Volatile Extraction

- Engineering Breadboard Unit (EBU) \#2 is under design.

- This is a field prototype that is flight-like in size.

- We would desire to add a Mass Spectrometer to the GC to allow GC/MS analysis which would allow greater sensitivity and the analysis of $\mathrm{H} 2 / \mathrm{HD} / \mathrm{D} 2 / \mathrm{He} 3 / \mathrm{He} 4$ mixtures.

- Currently we have no good candidate MS which can scan at $20 \mathrm{hz}$ over the range of 2-100 AMU to keep up with the GC separations.

- RESOLVE EBU2 field prototype will be completed in June of 2008

- Laboratory tests will be conducted in July \& August

- Field Test at a lunar analog location in November of 2008

- Mauna Kea, Hawaii is likely location 


\section{Water Analysis on PoraBond Q Column}

RESOLVE: Regolith \& Environment Science and Oxygen \& Lunar Volatile Extraction

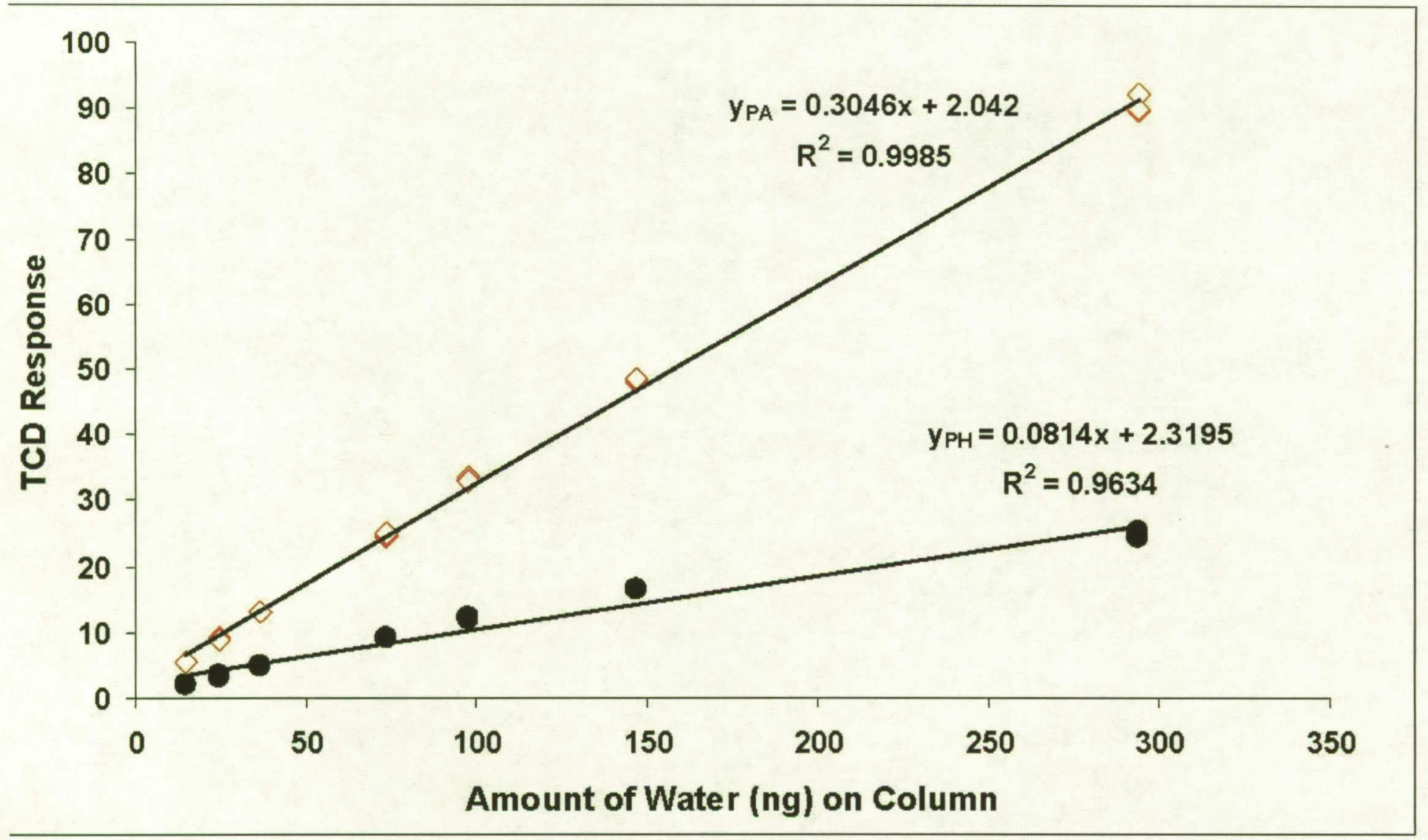

Figure 7. Calibration curve of water on CP-PoraBOND Q column 


\section{Gas Chromatograph Module}

RESOL VE; Regolith \& Environment Science and Oxygen \& Lunar Volatile Extraction

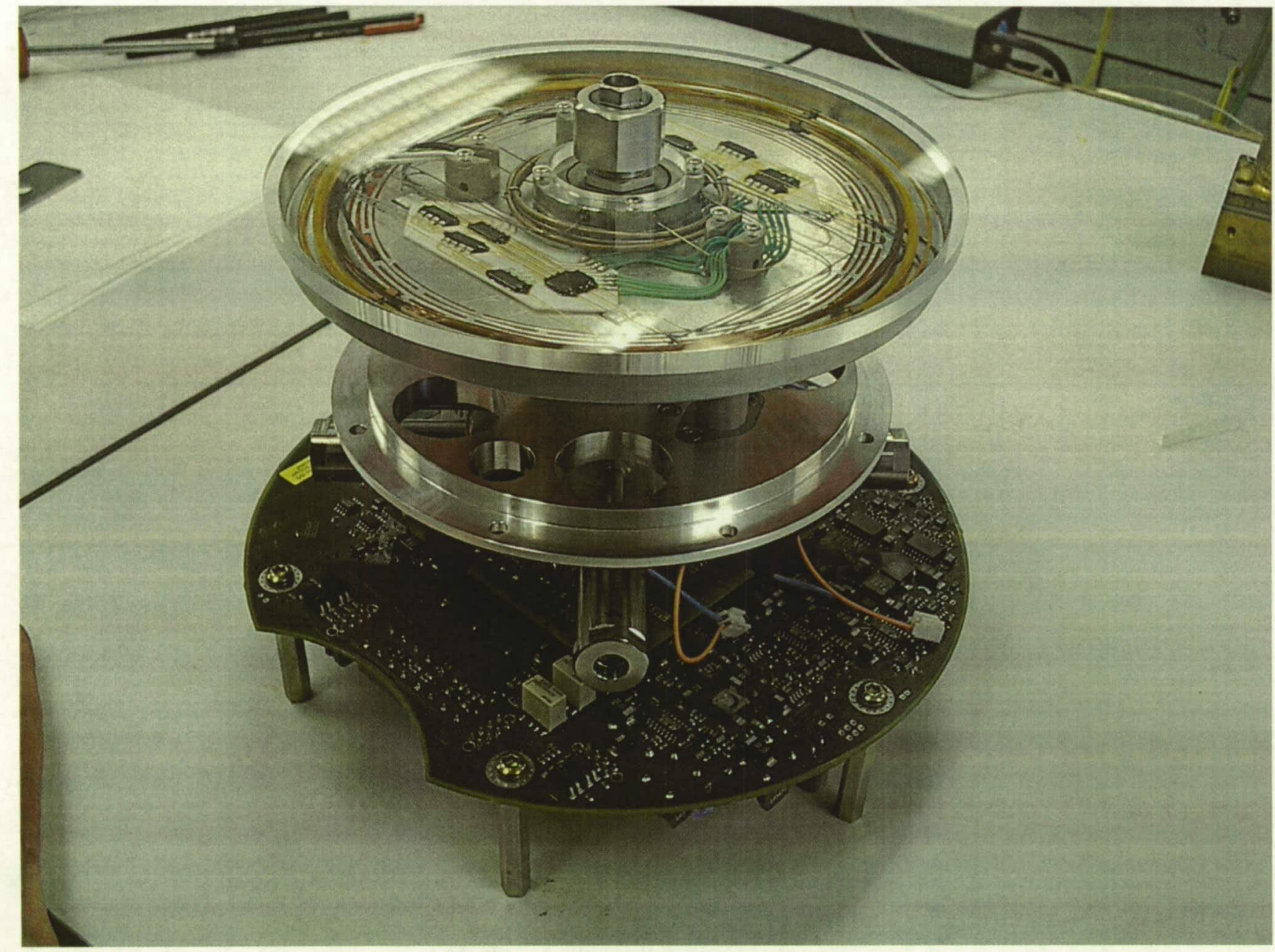




\section{CAD Model of Light Weight GC Case Design}

RESOL VE: Regolith \& Environment Science and Oxygen \& Lunar Volatile Extraction

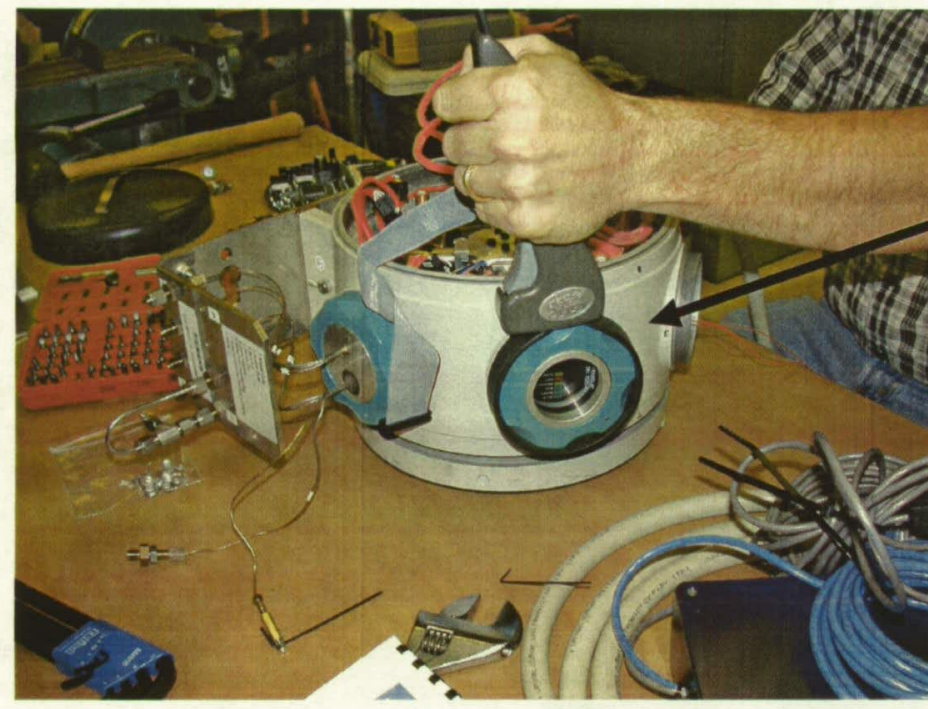

After: $10 \mathrm{lbs}$

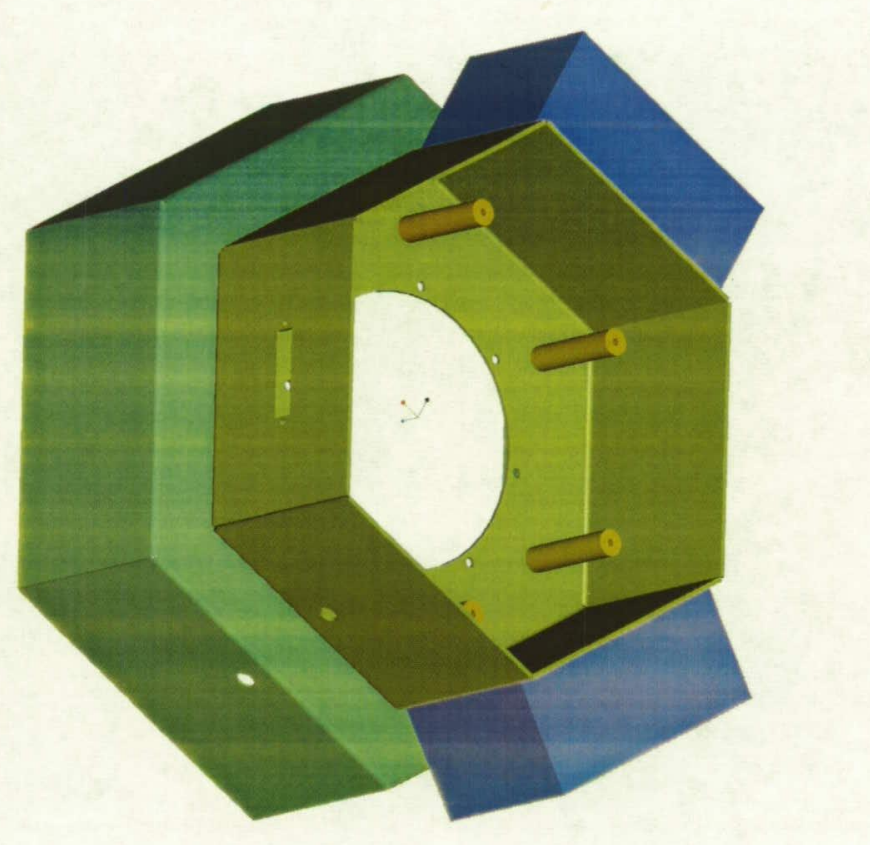




\section{Near Term Plans}

RESOLVE; Regolith \& Environment Science and Oxygen \& Lunar Volatile Extraction

- Fabricate Light Weight Enclosure

- Re-assemble MicroSAM

- Modify Application Module for Higher Water Concentrations and Lower Detection Limits

- Integrate with complete RESOLVE package and Rover (CMU)

- Integrated Testing begins in June

- Field Test and Demo on Mauna Kea November, 2008

- Future

- Flight re-design and to the Moon: 20?? 
Secondary Compounds of Interest: $\mathrm{CO}_{2}, \mathrm{CO}, \mathrm{NH}_{3}, \mathrm{CH}_{4}, \mathrm{H}_{2} \mathrm{~S}, \mathrm{O}_{2}, \mathrm{~N}_{2}, \mathrm{He}$

Detection Limits: Any compound under $100 \mathrm{AMU}$ and present in the evolved gases at a concentration of at least $0.5 \%$ by volume shall be detected, identified, and quantitated.

Identification: All compounds deemed essential to detect by the Science Advisory Team shall be positively identified by the analytical system within a mixture of some or all essential and secondary compounds of interest.

Quantitation: Errors in the quantitative analysis of each compound shall not exceed $0.2 \%$ by volume of the total evolved gases or $10 \%$ relative of the specific gas identified, whichever is greater.

Gas Sample Contaminants. All gas samples are evolved from regolith that contains up to $10 \%$ of particulates $<10 \mu$ in particulate size. These particulates are likely to travel with the gases into all collection beds, valves and analyzer sample inlet ports. Filtering to remove these particles will likely be only partially successful, allowing some particles of even smaller size to pass on through. Elimination of all fines is considered undesirable before analysis and capture of the adsorbed volatiles.

Thermal Location: The sample gas lines and all points the sample contacts will need to be warm enough to prevent condensation. For water, this would mean temperatures that are above $100^{\circ} \mathrm{C}$.

This paper will outline the steps taken in choosing a commercially available instrument system suitable for the analysis requirements and its modification for our particular application.

\section{ASSESSMENT OF VARIOUS ANALYTICAL SYSTEMS}

The requirements for measuring both hydrogen and water as essential analytes limit the choices for the analytical systems. While infrared absorptions systems can measure many of the compounds of interest, $\mathrm{H}_{2}, \mathrm{O}_{2}$, and $\mathrm{N}_{2}$ as well as any inert gases are not measured as they have no absorption bands in the infrared. Among general purpose systems that can measure all of the gases of interest, only gas chromatography (GC) and mass spectrometry (MS) appear to offer the detection limits and compound identification needed. The pros and cons of each technique are explored below.

\section{Mass Spectrometry}

In any mass spectrometer, the molecules to be analyzed enter into the evacuated spectrometer through an inlet; enter the ionization section where the molecules are, typically, bombarded with electrons to produce a series of ions typical of the molecules that entered and the energy of the electrons impacting them. These ions are then accelerated into the mass separation section where the various ions are separated based on their mass/charge ratios. The mass separation section operates on one of several principles for which the MS type is named.

\section{Time -of-Flight MS}

Time-of-Flight (TOF) MS has a flight tube through which the ions are accelerated through a fixed voltage to the detector. All the ions in each sample are analyzed sequentially, separated in time by the rate of acceleration through the fixed voltage. Arrival times are very short, requiring a very fast detector and $A / D$ converter to separate the rapidly arriving ions.

\section{Quadrupole MS}

Quadrupole MS utilizes four rods with RF fields imposed on them to "tune" the mass separation to one specific mass at a time. The field can be rapidly tuned sequentially to each unit mass to obtain a separation spectrum of ions. Ions closer together than 1 unit mass will be read as the same mass. The RF field generators are fairly complex and require calibration in near real-time. Detector data rates are much lower than with TOF, since the total charge can be accumulated for a single mass and read out only once for each analysis.

\section{Magnetic Sector MS}

Magnetic Sector MS accelerate the ions through a constant voltage and then pass the ions into a magnetic field that causes each ion to follow a curved path based on its mass/charge ratio. Light ions curve more sharply than heavier ions, varying the detector position where they strike and are detected. A detector array separates the different 
masses. Low data rates and a permanent magnet characterize a magnetic sector MS. Small size sectors can achieve separation with small, light-weight magnets.

\section{Pros and Cons of Mass Spectrometry}

MS requires no consumable gases for basic operation, unlike a GC. Each compound gives a specific pattern of ions that helps to identify the original molecule without specific calibration for that compound. IE, identification (but not quantitation) is possible without calibration. Since the major weight in a mass spectrometer is the vacuum pump system, we can lighten the system weight considerably for use on the Moon, where superior vacuum is available in abundance. Since the core MS detector operates at very low pressure, it is possible to sample from a variety of pressure sources if a variety of sample inlet restrictions are provided. This might allow a single instrument to sample the lunar atmosphere (1E-10 torr) as well as the high pressure $(\sim 5 \mathrm{~atm})$ volatiles derived in the RVC. However, this range of pressures (over 13 orders of magnitude) would be a serious challenge for the sample inlet design.

The analysis of water vapor in a mass spec presents several challenges. Water vapor is very "sticky", leaving residues attached to various parts of the MS inlet and internal structures. At least one manufacturer suggested the problem is intrusion of ambient water vapor through the seals on a MS on Earth. If this is the true source of the problem, then the problem would not exist on the Moon or Mars. Clearly, the source and existence of this problem should be proven before a solution is implemented. These residues can persist for some time and give false signals or very high baseline concentration of water even when current samples have no water in them. Identifying that the background signal has changed would be a major problem in a continuous analyzer attached to the RVC oven exhaust. Without a known or low baseline, quantitative results would be difficult or impossible. This problem can be reduced by operating the MS at high temperatures where water can not condense and adhere to surfaces easily.

The water itself is quite stable, but when ionized is very reactive, forming new compounds with other ions or compounds that may be present in the sample. Thus the signal for water may be matrix dependent in a MS. These effects are mitigated by operating the ionizer and separation sections at low pressures. Then the mean-free-path would make reactive collisions unlikely. But, this would also lower the signal levels and reduce the accuracy of the quantitation.

Ion masses can be populated by other molecules or ions of the same mass. This can cause some confusion in a complex matrix. This is not a new problem, and standard MS software can analyze these situations with multicomponent simultaneous equations. However, the accuracy of the results suffers in such systems and can become the dominant source of errors in a complex system that has not been separated prior to the MS analysis. Manufacturers of Thermo-gravimetric Analyzers (TGA) have begun offering MS analyzers as an add-on to quantitate and identify the effluent gases. Attempts to use the MS signal for the quantitation of water evolved from the samples have not been very good. The use of signal integration techniques on single mass plots vs. temperature of evolution produced large errors even with known pure compounds as standards and known mixtures for samples. Results were typically low, compared to TGA weight losses, by up to $25 \%$. In earlier work with a reverse water gas shift (RWGS) reactor at KSC, attempts to use MS for analysis of the recirculating gas stream were of limited success. Material balance calculations were typically off by $20-30 \%$. Our MS experts could only point to matrix effects that could be solved by better standards with compositions closer to the actual gas compositions. The experiences with the RWGS experiments are particularly troublesome, as the gases in the RWGS system include many of the same gases we are concerned with in the RESOLVE project: $\mathrm{H}_{2}, \mathrm{CO}_{2}, \mathrm{CO}$, and $\mathrm{H}_{2} \mathrm{O}$ in various concentrations. Indeed, the RWGS case is better defined and has less possible variations than the RESOLVE case. In the RWGS experiment we obtained excellent mass balances by switching our analytical system to GC.

\section{Gas Chromatography}

Gas Chromatography (GC) analysis is a method to separate a mixture of gases and then measure each separate component on a universal detector. The separation is done by passing the mixture of gases over a stationary coating or packing that attracts the differing molecules to a greater or lesser degree. The stationary phase is commonly contained in a long thin tube made of SS or fused silica, with the combination of the tube and stationary phase coating or packing known as a chromatographic column. The name is derived from early experiments in which the color components in mixtures were separated to produce a "color graph" or chromatogram of the separated dyes. In 
gas chromatography, all the components to be separated must be in the gas phase to be carried through the column by a moving carrier gas stream, with each component being delayed (or "retained") in proportion to the attraction each molecule has to the stationary phase. GC systems have been in common use since the 1950's, with many advances in all facets of the system, including injection valves, column switching, column design, stationary phases, oven design, and detectors. The recent development efforts have been put into the design of miniature GC systems utilizing silicon chip detectors and valves to achieve very small systems with much faster separations. These systems typically use a thermal conductivity detector that employs a thin platinum wire or film suspended in a small channel in a silicon chip. By orienting the platinum wire coaxial with the gas flow, and heating the wire, the wire temperature responds primarily to changes in the gas stream's thermal conductivity, given careful control of the temperature and gas flow rates.

\section{Pros and Cons of Gas Chromatography}

GC has the advantage of separating the compounds to be measured, which greatly reduces the possibility of confusion over what compounds were present. This process is essential when the detector provides no identification information, which is the case with a TCD detector. In this case the sole means of identification is the elution time, which will require careful control of the column and inlet temperatures as well as carrier gas flow rates. Combining a GC with a MS as the detector yields a much more powerful tool than either technique done separately. GC systems require the use of a carrier gas. The containment tank and the flow controls add weight to the system. For long periods of operation, the carrier gas supply can become the major weight component of the analytical system. Samples containing many compounds can become difficult to analyze with a universal detector, as complete separation of many peaks is often not realized in practice, especially where an unknown compound might occur. In the case of an unknown compound, no data to aid in identification is obtained other than the retention time.

\section{System Selection}

GC was selected as the initial analytical system for several reasons. Since we were looking for a developed and affordable system that could analyze the gases of interest and several GC manufacturers had systems set up for those gases, it was a matter of finding an appropriately designed system for potential unattended operation. This led to a survey of automated miniature GC systems that could be fully automated. Three potential candidates emerged among the commercial miniature GC systems. The earliest system is currently marketed by Agilent and is the outgrowth of a MEMS GC first devised at Stanford in the 1970's. It has been well developed into a field portable system with up to 4 separate modules for various analyses. The second is from Varian, with a somewhat similar design with separate modules, each keyed for separate analyses using separate gas flows and injections for each module. The third is a MEMS design of a process GC from Siemens, intended for field mounting in a chemical plant. This system allows a single injection to be analyzed on multiple columns, a technique known as multidimensional chromatography. Since they already had an application module that would do all of our separations, including water and hydrogen separations along with most of our other gases, we elected to use this instrument as the start for our design. While the Siemens MicroSAM process GC had many of the attributes we were looking for, some of the things we wanted would require modification of their standard application.

\section{SYSTEM DESCRIPTION}

The application module of the MicroSAM contains all of the active components of the GC. It has 8 thermal conductivity detectors (TCD) arranged in 4 pairs, a multi-port diaphragm valve used for sampling and backflush operations, a programmable on-column fluidic injection system, up to 4 columns, and a dean's switch for doing a heart cut onto the last analytical column, a molecular sieve column in our case. All of these components are contained in a single temperature controlled module $1.1 \mathrm{~cm}$ thick by $16.1 \mathrm{~cm}$ in diameter. This application module is attached to the electronic controls through 3 multi-pin connectors and a series of spring loaded pneumatic connections in the central hub that lead to 3 programmable electronic pressure controllers (EPC). During operation, the application module is operated isothermally to eliminate the cool down period associated with temperature programming. The third EPC is programmed to allow only the permanent gases to enter the mole sieve column. As received, all peaks have eluted and the back flush is completed in $220 \mathrm{sec}$. With a 10 second sample flush time 
before the next injection, a complete cycle time of $240 \mathrm{sec}$ is achieved on a continuous run basis, including the data transfer to the host computer. As received, the module could analyze all the permanent gases: $\mathrm{H}_{2}, \mathrm{He}, \mathrm{O}_{2}, \mathrm{~N}_{2}, \mathrm{CH}_{4}$, and $\mathrm{CO}$ along with $\mathrm{CO}_{2}, \mathrm{H}_{2} \mathrm{O}$, and $\mathrm{H}_{2} \mathrm{~S}$. Also included, but not of interest to us, were light hydrocarbons up to $\mathrm{C}$. The module is normally operated on Helium carrier gas except for $\mathrm{H}_{2}$ and $\mathrm{He}$ analysis, which can be run on argon or nitrogen.

\section{SYSTEM MODIFICATION}

While the module as shipped can separate all of the gases we want, the use of helium as the carrier gas precludes a helium analysis. Also, the detection limits for hydrogen would be poor with a helium carrier gas and the response at high concentrations of hydrogen is often reported as non-linear using a helium carrier gas. Since we want all of our analytes quantitated on a single run and a single carrier gas, we decided on a neon carrier gas because its thermal conductivity is intermediate between $\mathrm{H}_{2} / \mathrm{He}$ and most of the other gases. Neon is somewhat close to the thermal conductivity of methane, so we expected a decreased signal for methane, one of our secondary analytes. The thermal conductivity of several gases of interest at $400 \mathrm{~K}$ is shown in Table 1 below.

TABLE 1. Thermal Conductivity of Selected Gases at 400K (Lide, 1998-9).

\begin{tabular}{c|l|c}
\hline Molecular Formula & Name & Thermal Conductivity $(\mathbf{m W} / \mathbf{m ~ K})$ \\
\hline $\mathrm{Ar}$ & Argon & 22.6 \\
$\mathrm{H}_{2}$ & Hydrogen & 230.4 \\
$\mathrm{He}$ & Helium & 190.6 \\
$\mathrm{Ne}$ & Neon & 60.3 \\
$\mathrm{O}_{2}$ & Oxygen & 33.7 \\
$\mathrm{~N}_{2}$ & Nitrogen & 32.3 \\
$\mathrm{H}_{2} \mathrm{O}$ & Water & 27.1 \\
$\mathrm{CH}_{4}$ & Methane & 49.1 \\
$\mathrm{CO}_{2}$ & Carbon Dioxide & 25.1 \\
$\mathrm{CO}$ & Carbon Monoxide & 32.3 \\
\hline
\end{tabular}

Since the thermal conductivity of neon is quite different from helium or argon, the two carrier gases typically used on this GC, the settings for the power level for the TCD detectors would have to be derived from the settings used for these gases versus their thermal conductivity. The gas properties immediately adjacent to the detector filament (a thin platinum film) are the most important factor in preventing detector burn out. The maximum power levels for the TCD's were published for Ar, N2, He, and H2 carrier gases. Since the filament is much hotter than the detector body (about $400 \mathrm{~K}$ ), we selected thermal conductivity data in the range of $500-600 \mathrm{~K}$ for determining the interpolated power level for neon carrier gas. Since complete data was not readily available for all the gases at all the temperatures, some of the data was calculated as indicated by values in italics. Table 2 and Figure 1 show the data, curve fit, and results (Lide, 1998-9).

TABLE 2. Maximum Allowable Power vs. Thermal Conductivity for Carrier Gases in MicroSAM GC,

\begin{tabular}{l|l|r|r|r}
\hline Gas Name & Maximum & \multicolumn{3}{|c}{ Thermal Conductivity, mW/m K } \\
\cline { 3 - 5 } & Power $(\mathbf{m W})$ & $\mathbf{5 0 0} \mathbf{~}$ & $\mathbf{5 2 3} \mathbf{~ K}$ & $\mathbf{6 0 0 ~ K}$ \\
\hline Argon & 28 & 26.8 & 39.6 & 44.0 \\
Helium & 115 & 222.3 & 230.0 & 252.4 \\
Hydrogen & 115 & 274.0 & 280.0 & 300.0 \\
Neon & $\mathbf{4 6}$ & 69.9 & 73.5 & 78.7 \\
\hline
\end{tabular}

The curve fit in Figure one was used to calculate maximum power value shown in Table 2 for neon. With the estimated maximum bridge power in hand, we proceeded to set the TCD bridge voltages to $900 \mathrm{mV}$, giving a typical bridge power of $35 \mathrm{~mW}$ on neon. Using this setup, we injected a 6 component calibration gas mixture (Table 3 ) to test the system.

TABLE 3. Six-Component Calibration Gas Mixture.

\begin{tabular}{llllllll}
\hline Gas & $\mathrm{H}_{2}$ & $\mathrm{CH}_{4}$ & $\mathrm{O}_{2}$ & $\mathrm{~N}_{2}$ & $\mathrm{CO}$ & $\mathrm{CO}_{2}$ & $\mathrm{He}$ \\
Conc., Vol \% & 4.00 & 4.00 & 5.00 & 5.00 & 5.00 & 5.00 & $\mathrm{Bal}$ \\
\hline
\end{tabular}




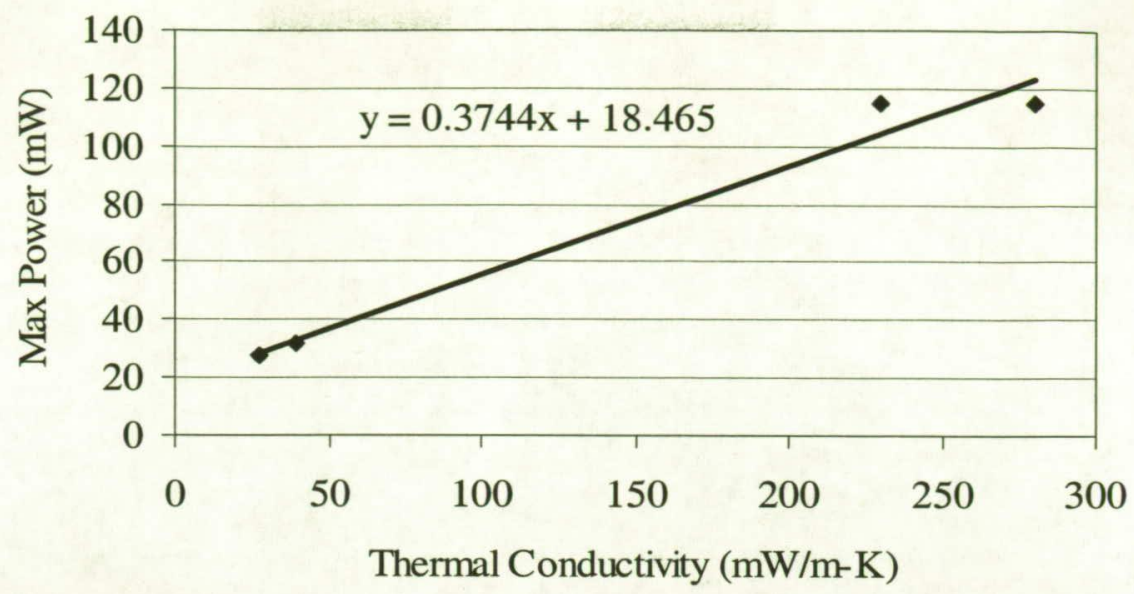

FIGURE 1. Maximum TCD Bridge Power vs. Thermal Conductivity of Carrier Gas at $523 \mathrm{~K}$.

For water calibration we built a custom 2-pressure humidity generator from spare parts, a purchased consumer cooler, and a precision thermistor temperature probe. This system worked well, but the water analysis on the GC had a few problems. With the as-shipped application software, the column temperature was only $333 \mathrm{~K}$, too low for even moderate water vapor concentrations. As problems persisted even at a column temperature of $383 \mathrm{~K}$, we determined that the inlet lines and sample loop inside the application module needed additional heat to ensure that condensation of the water vapor did not occur. We wrapped the critical areas with insulated nichrome wire, and silanized the inlet tubing using dimethyl ethoxy silane (DMES) the Shuttle tile waterproofing agent, which is a vapor at the temperatures in this GC module. We were limited to a maximum temperature of $383 \mathrm{~K}$ by the loss of separation on the mole sieve column at higher temperatures. The application for our analysis includes columns for the higher hydrocarbons and a pre-column that might adsorb injected water vapor. The flow schematic as received is shown in Figure 2. By bypassing the first two columns and detector pair 3A \& B, we achieved the schematic shown in Figure 3. A photo of the inside of the application module, Figure 4, gives some idea of the difficulty in modifying a MEMS assembly with no fittings and only cemented joints on $0.25 \mathrm{~mm}$ fused silica tubing.

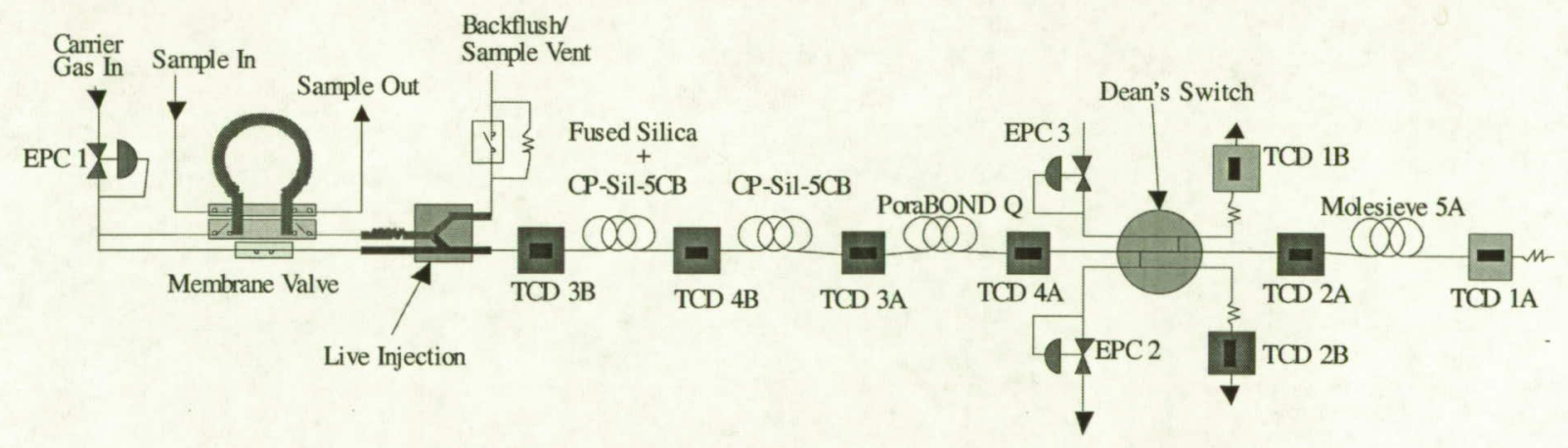

FIGURE 2. As Received Application Module Flow Schematic

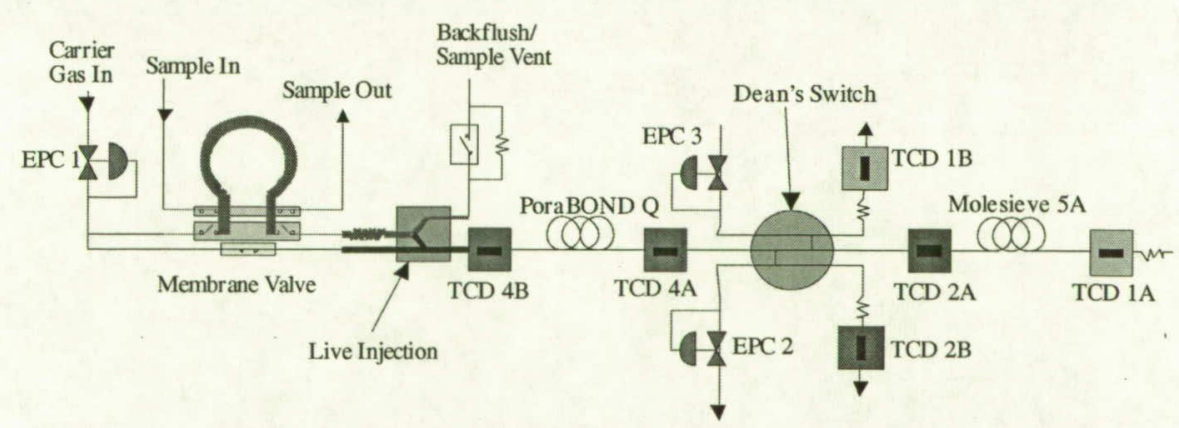

FIGURE 3. Modified Application Module Flow Schematic 


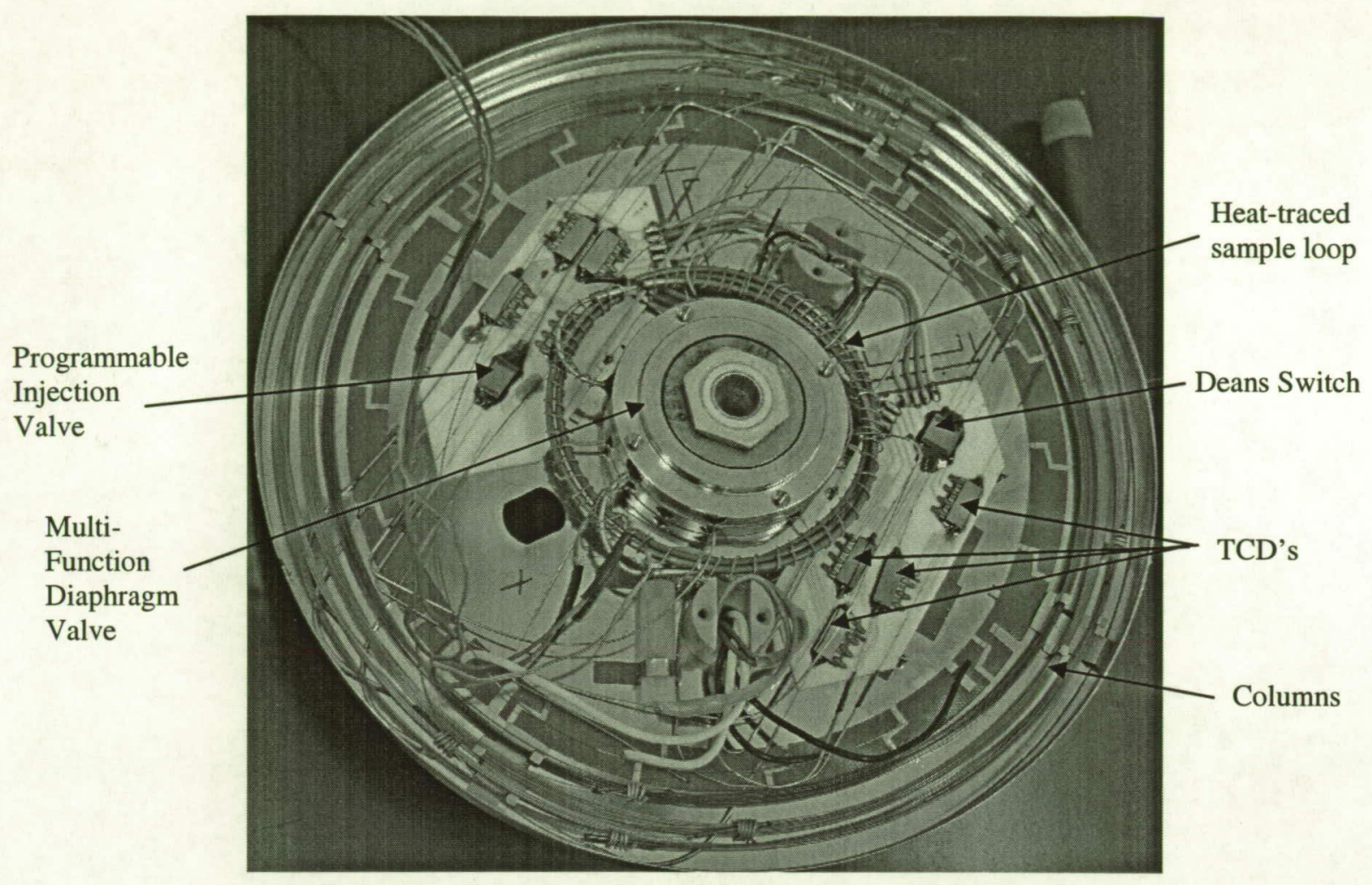

FIGURE 4. Modified Application Module with Cover Removed, 90\% of Actual Size

\section{RESULTS}

After completion of the modifications described, we proceeded to test the GC system and integrate it with the RESOLVE oven (designed by John H. Glenn Research Center) and the Lunar Water Resource Demonstration led by J. Captain at KSC. Some typical calibration results and a sample chromatogram are shown. Mass balances with the known contents of the oven were good during the initial integrated testing.

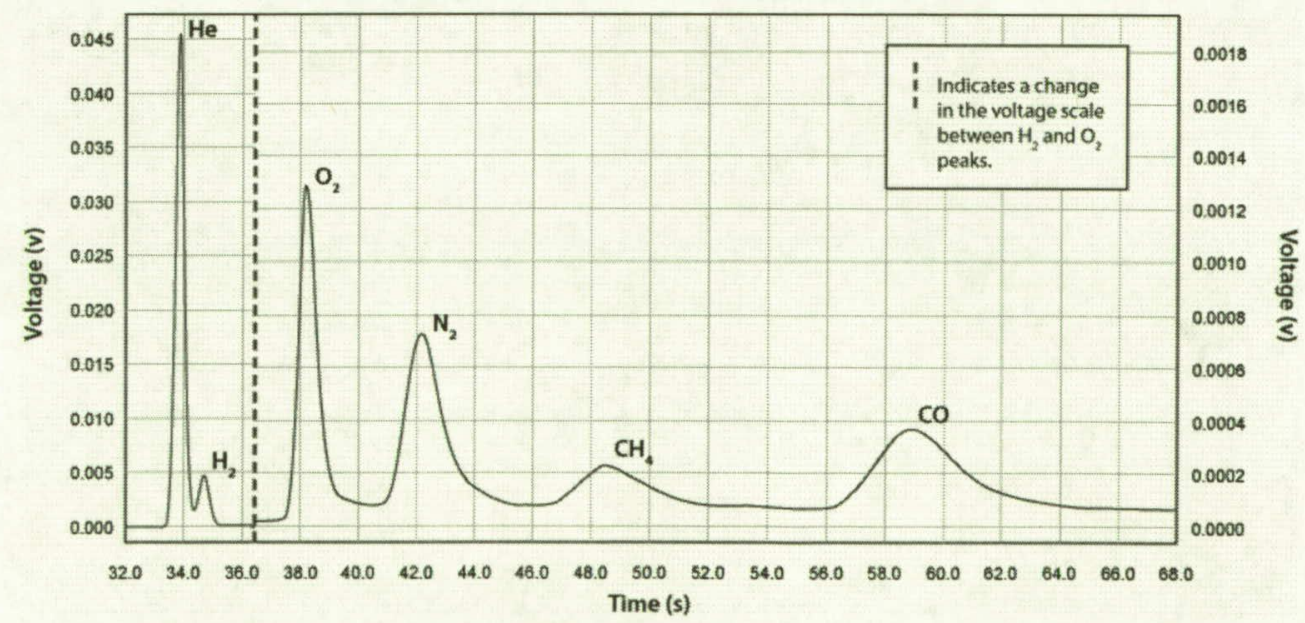

FIGURE 5. Chromatogram of $6 \mathrm{Gas}$ Standard, $\mathrm{CO}_{2}$ Not Shown. 


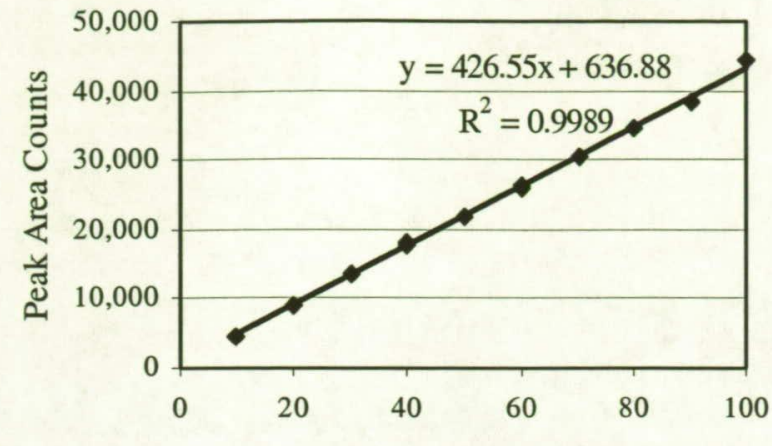

Hydrogen Concentration, vol\%

FIGURE 6. Hydrogen Calibration Curve, High Range.

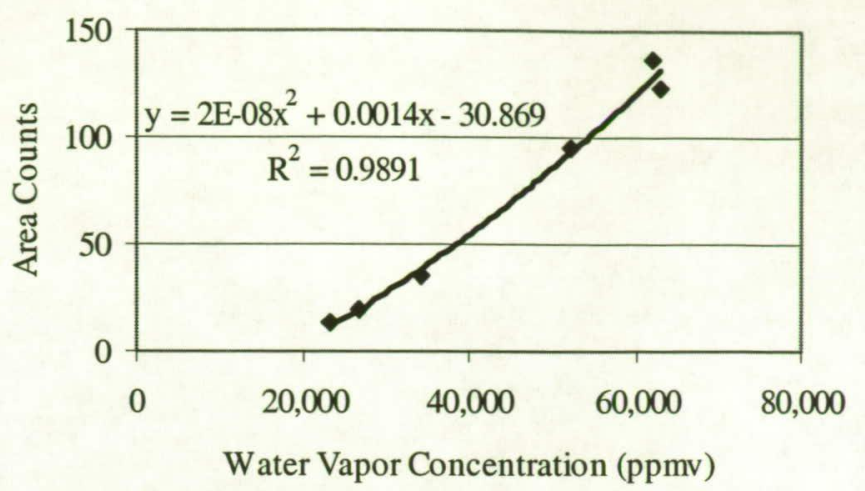

FIGURE 7. Water Vapor Calibration Curve, Low Range.

\section{CONCLUSIONS AND FUTURE WORK}

The water calibration curves continue to show a non-zero intercept at about $15,000 \mathrm{ppm}$ water vapor concentration. This is marginally acceptable for our use and we hope to achieve improved results with the changes planned for the second breadboard version, EBU2. The changes that would address the water detection limit problem include mounting the mole sieve column into a new lower temperature oven and the testing of other porous polymer columns than the presently used PoraBond-Q column supplied by Siemens. The separate oven will allow higher temperatures for the injection and water separation. At least $420 \mathrm{~K}$ is needed for the higher water concentrations from the RVC oven. A better column would have less of a polar character than the PoroBond-Q. Coupled with the higher column temperatures, improved performance is expected on both the high and low water vapor concentrations. The removal of the outer explosion proof case will lower the weight of the GC assembly below 5 $\mathrm{kg}$. Lastly, we would still like to find a miniature MS with 2-100 AMU capability and a fast scan rate $(\sim 10$ scans/sec or higher) to couple with this GC. The combination of the two analyzers would allow the determination of $\mathrm{H} 2 / \mathrm{HD} / \mathrm{D} 2$ and $\mathrm{He} 3 / \mathrm{He} 4$ as well as any unknowns that may be encountered.

\section{ACKNOWLEDGMENTS}

The author thanks the NASA Exploration Technology Development Program for their continued funding for this program, Jerry Sanders at JSC for his tireless promotion of ISRU, and Bill Larson at KSC for his leadership and belief in the Applied Sciences Division at KSC.

\section{REFERENCES}

Feldman, W. C., et al., "Fluxes of Fast and Epithermal Neutrons from Lunar Prospector: Evidence for Water Ice at the Lunar Poles," Science 281, p. 1496 (1998)

Feldman, W. C., et al., "Evidence for Water Ice Near the Lunar Poles," J. Geophys. Res. 106, 23231-23251(2001).

Lide, D.R., editor, "Thermal Conductivity of Gases," in CRC Handbook of Chemistry and Physics, 79 ${ }^{\text {th }}$ Ed, 6-175-6-176 (19989).

Lide, D.R., editor, "Properties of Carrier Gases for Gas Chromatography," in CRC Handbook of Chemistry and Physics, $79^{\text {th }}$ Ed, 8-119 (1998-9).

Nozette, S., et al., "The Clementine Bi-static Radar Experiment,” Science 274, pp. 1495-1498 (1996) 